Sixteen further patients have been treated with allopurinol, because it was thought to be specially indicated in preference to uricosuric treatment. The main reasons for this were adverse reactions to uricosuric agents, renal failure, and inadequate control of gout by uricosuric drugs. The response to allopurinol was again very satisfactory.

No serious toxic effects were encountered. Scvere attacks of acute gout can follow the rapid lowering of serum uric acid either by allopurinol or by uricosuric drugs. This makes it worth while starting with low doses and giving an additional drug-for example, colchicine-to suppress acute attacks during early months of treatment.

An unexpectedly high-incidence of abnormalities in the sulphobromophthalein (Bromsulphalein) excretion test, and to a smaller extent in other tests of liver function, was found in patients taking allopurinol and in those on uricosuric treatment. The reason for this is not apparent, but there is no evidence that either type of drug treatment was responsible.

It is as yet uncertain whether allopurinol will replace uricosuric treatment as the standard method of lowering the serum uric acid. Certain situations are discussed where allopurinol seems to be clearly the treatment of choice.

We wish to thank Dr. Ruth Haslam and other members of the Department of Chemical Pathology, Hammersmith Hospital, for carrying out most of the biochemical procedures in this study; the Haematology Department for the blood investigations; Dr. S. R. M. Bushby and members of the Wellcome Research Laboratories for certain tests of hepatic function; and the Wellcome Foundation Limited, who supplied the allopurinol (Zyloric).
REFERENCES

Ayvazian, J. H. (1964). New Engl. f. Med., 270, 18.

DeConti, R. C., and Calabresi, P. (1966). Ibid., 274, 481

Delbarre, F., Auscher, C., Labrousse, C., and de Gery, A. (1965). Presse méd., 73, 1275 .

Denman, A. M., Huber, H., Wood, P. H. N., and Scott, J. T. (1965), Ann. rheum. Dis., 24, 278.

Dent, C. E., and Philpot, G. R. (1954). Lancet, 1, 182.

Dickinson. C. J., and Smellie, J. M. (1959). Brit. med. F., 2, 1217.

Engelman. K., Watts, R. W. E., Klinenberg, J. R., Sjoerdsma, A., and Seegmiller, J. E. (1964). Amer. 7. Med., 37, 839.

Ferris, T. F., Morgan, W. S., and Levitin, H.' (1961). New Engl. F. Med., 265, 381 .

Goldfinger, S., Klinenberg, J. R., and Seegmiller, J. E. (1965). F. clin. Invest., 44, 623.

Green, S., and Mazur, A. (1957). 7. biol. Chem., 227, 653.

Hall, A. P., Holloway, V. P., and Scott, J. T. (1964). Ann. rheum. Dis., $23,439$.

Houpt, J. B. (1965). Arthr. and Rheum., 8, 899 Klinenberg, J. R., Goldfinger, S. E., and Seegmiller, J. E. (1965). Ann.

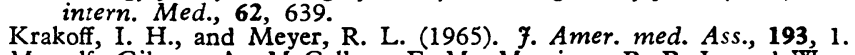

Metcalfe-Gibson, A., McCallum, F. M., Morrison, R. B. I., and Wrong, O. (1965). Clin. Sci., 28, 325 .

Powell, L. W., and Emmerson, B. T. (1966). Lancet, 1, 239.

Rapado Errazti, A. (1965). Rev. clir. esp., 98, 133.

Reynolds, E. S., Schlant, R. C., Gonick, H. C., and Dammin, G. J. (1957). New Engl. 7. Med., 256, 592.

Rundles, R. W., Elion, G. B., and Hitchings, G. H. (1966). Bull. rheum. Dis., 16, 400

Metz, E. N., and Silberman, H. R. (1966). Ann. intern. Med., 64, 229 .

Wyngaarden, J. B., Hitchings, G. H., Elion, G. B., and Silberman, H. R. (1963). Trans. Ass. Amer. Phycns, 76, 126.

Seegmiller, J. E., and Howell, R. R. (1962). Arthr. and Rheum., 5, 616. Smyth, C. J. (1965). Ibid., 8, 907.

Watts, R. W. E., Watkins, P. J., Matthias, J. Q., and Gibbs, D. A. (1966). Brit. med. F., 1, 205.

Wolfson, W. Q., Cohn, C.., Levine, R., Rosenberg, E. P., and Hunt, H. D. (1949). Ann. intern. Med., 30, 598.

Yü, T. F., and Gutman, A. B. (1964). Amer. F. Med., 37, 885.

\title{
Exercise Electrocardiogram in Myxoedema
}

\author{
R. D. COHEN,* M.A., M.D., M.R.C.P. ; H. G. LLOYD-THOMAS, † M.A., M.D., M.R.C.P.
}

Brit. med. F., 1966, 2, 327-330

It is accepted that symptoms of cardiac ischaemia may be precipitated by treatment of myxoedema. It has therefore been the usual practice to treat patients in the older age groups with very slowly increasing doses of thyroid hormone. The exercise electrocardiogram (E.C.G.) has been extensively used as a more sensitive detector of cardiac ischaemia than the resting record (Master, Field, and Donoso, 1957 ; Lloyd-Thomas, 1961a, 1961b). We have studied the exercise E.C.G. in myxoedema, with the initial object of detecting ischaemia which might be exacerbated on treatment. The clinical and patho-physiological implications of the findings are discussed in the light of present knowledge of myocardial function in myxoedema.

\section{Patients and Methods}

The studies were performed on 12 patients with classical primary myxoedema and one with hypothyroidism following thyroid surgery. Hypothyroidism was confirmed by measurement of basal metabolic rate, thyroidal uptake of radioiodine, or plasma protein-bound iodine. Their average age was 42.4 years (range 15-62). Details of these patients are shown in Table I. No patient had a history suggestive of cardiac pain, nor were there any physical features of heart failure. After patients had rested for 30 minutes a resting E.C.G. was recorded (leads I, II, III, IIIR or AVF, $\mathrm{CR}_{1}, \mathrm{CR}_{4}$, and $\mathrm{CR}_{6}$ or $\mathrm{CR}_{7}$ ).

* Senior Lecturer, Medical Unit, the London Hospital.

t Consultant Physician, St. Andrew's Hospital, Bow, London.
The E.C.G. was then repeated after exercise in the manner described by Lloyd-Thomas (1961a). Usually 50 to 100 ascents and descents of the staircase were accomplished in five to eight minutes.

The post-exercise E.C.G. recordings were commenced two minutes after exercise ended and continued for 10 to 20 minutes. E.C.G.s were recorded by means of a direct-writing electrocardiograph. The sensitivity was always $1 \mathrm{mV} / \mathrm{cm}$.

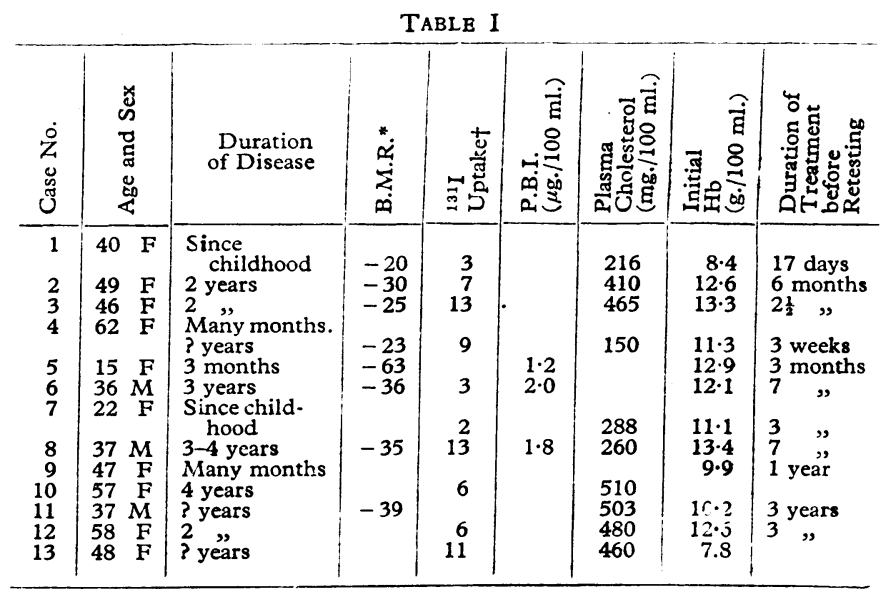

* Referred to standards of Robertson and Rei 1 (1952).

$+\%$ neck uptake of dose at 24 hours. 
When analysing the records care was taken to use only those portions of the tracings in which the baseline was absolutely steady. The junction of the QRS complex and the S-T segment is referred to as $\mathrm{J}$.

In 11 patients the test was repeated at a variable time from the start of treatment (see Table I). At the second test the number of ascents and descents was increased in approximate proportion to the ratio of the weights of the patient before and after treatment, and the test was performed in approximately the same time as previously. Thus both the total work done and the rate of working before and after treatment were roughly comparable.

No patient developed cardiac pain after treatment, nor did pain occur during the exercise tests.

\section{Exercise E.C.G. Before Treatment}

All patients developed changes after exercise in one or more leads. These are summarized in Table II. Attention has chiefly been paid to the $S-T$ and $T$ segments of the records. The most frequently observed changes were inversion of $T$ wave in nine cases (in lead III alone in two cases), development of a sagging $S-T$ segment (10 cases), and increase in depth of already present $T$-wave inversion (six cases). To the last group may be added three cases in which an initially flat $T$ wave became inverted. Other changes observed were depression of $\mathrm{J}$ of at least $1 \mathrm{~mm}$. (four cases), lowering of amplitude of upright $T$ waves (two cases), development of a plane S-T segment (one case), and transient heightening of $\mathrm{T}$ wave within two minutes after exercise (four cases). The changes usually disappeared within 9 to 25 minutes after the end of the exercise.

\section{Exercise E.C.G. After Treatment}

In 9 out of 11 patients tested again after treatment the resting E.C.G. was normal or nearly so. In Case 4, who was retested only three weeks after the start of treatment, the resting record was still of low voltage, with rather low $T$ waves in a few leads. In three patients on treatment no changes were observed in the E.C.G. after exercise (Cases 1, 7, and 11). In Cases 2, 9, and 12 sagging $S-T$ segments seen on exercise before treatment were now absent; inversion of $T$ waves no longer occurred, nor did marked reduction of amplitude of upright $\mathrm{T}$ waves. Minor reductions in upright $\mathrm{T}$ amplitude did occur. After treatment Case 2 developed a 1-mm. depression of $\mathrm{J}$ in lead $\mathrm{CR}_{4}$, but the $\mathrm{S}-\mathrm{T}$ segments were normal. In Case 6 the only change on exercise after treatment was a $30 \%$ reduction of upright $\mathrm{T}$ amplitude. Case 3 continued to show $\mathrm{T}$-wave elevation after exercise after treatment, but the sagging $S-T$ segment and inverted $T$ wave in $C_{4}$ did not occur. In Case 4, who was retested only three weeks after the start of treatment, at which time the resting record still showed marked reduction of voltage, the pre-treatment exercise abnormalities had disappeared but a plane configuration of the S-T segment developed in II, $\mathrm{CR}_{4}$, and $\mathrm{CR}_{6}$. In Case 5, the only patient suffering from myxoedema of acute onset, the main changethat is, elevation of $\mathrm{T}$ waves in many leads-was present both before and after treatment.

An example of the exercise changes before and after treatment is given in the accompanying Figure.

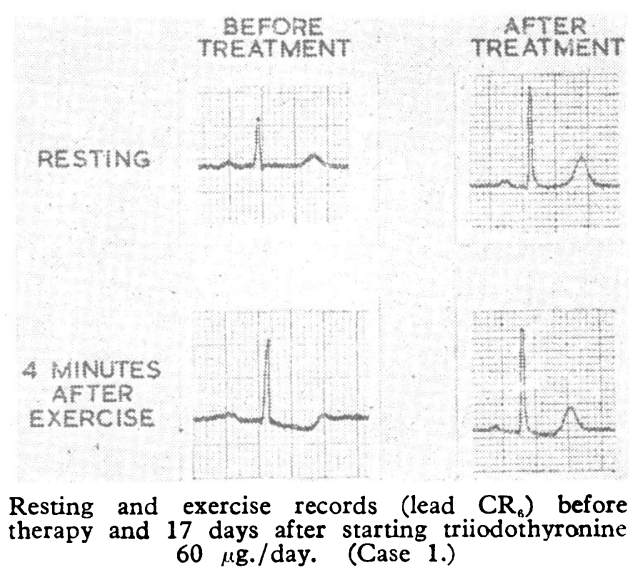

\section{Discussion}

We have been unable to find reports of similar studies in the literature. These results show that changes in the E.C.G. on exercise occurred in all the tested cases. The reason for the occurrence of these changes is uncertain, but in many respects they resemble those developing on exercise in patients with cardiac ischaemia. In particular, the sagging S-T segment on exercise is highly characteristic of ischaemic heart disease ; this abnormality, or plane deformity, occurred in $83 \%$ of 155 cases of cardiac ischaemia; $\mathrm{J}$ depression occurred in $67 \%$ of the cases. The significance of pure $\mathrm{T}$-wave changes is less certain, and it seems possible that $\mathrm{T}$-wave inversion after exercise may occur in patients who do not subsequently have an abnormally high rate of coronary occlusion (Master et al., 1957 ; Robb, Marks, and Mattingly, 1956); nevertheless, pure $T$-wave inversion is very uncommon in normal subjects on exercise, for in one series of 67 normal subjects the $\mathrm{T}$-wave amplitude never decreased to less than $33 \%$ of its original amplitude on exercise, and no examples of flat or inverted $\mathrm{T}$ waves were encountered (Lloyd-Thomas, 1961a).

Two of the patients with myxoedema showed only $\mathrm{T}$-wave changes on exercise and three had initially inverted $T$ waves temporarily corrected by exercise, an effect noticed in over $50 \%$ of patients with ischaemic heart disease who had $\mathrm{T}$-wave inversion at rest (Lloyd-Thomas, 1961b). It was also noted that in ischaemic heart disease a $\mathrm{T}$ wave of abnormally low voltage might be corrected by exercise. This effect was noted in Case 5, but since it persisted long after she had been rendered euthyroid it cannot be attributed to the hypothyroid state. The only other change in this patient on exercise before treatment was the development of an inverted $\mathrm{T}$ wave in lead III. Though

TABLE II.-Analysis of the Effect of Exercise on the S-T Portion of the E.C.G. Before Treatment

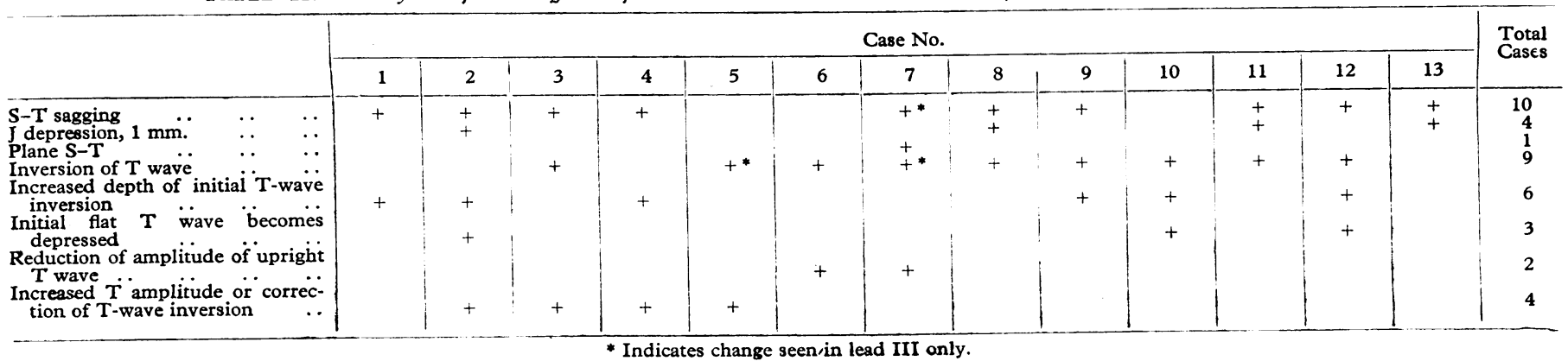


this did not appear after treatment its significance is doubtful, since a marked change in the electrical position of the heart had occurred.

A feature of the present findings is the tendency for the abnormalities to disappear on treatment. Three cases show no exercise changes after treatment. In Cases $2,3,6,8,9$, and 12 the changes remaining after treatment were now within the range of normal as defined by Lloyd-Thomas (1961b). In Case 4 very little time had elapsed after the start of treatment, and "ischaemic"-like changes were still present to some degree on retesting. Thus it may be said that in 11 cases tested before and after treatment the changes after exercise were restored to normal in nine and were partially restored in one. In the remaining case (No. 5) the post-treatment exercise record was not really different from that before treatment ; however, this patient had myxoedema of very acute onset (within three months of a partial thyroidectomy for thyrotoxicosis). She was also the youngest patient in the series (aged 15).

The resemblance of the exercise changes to those seen in ischaemia does not necessarily mean that they are actually due to ischaemia. The changes described could be non-specificfor instance, similar changes may occur after digitalis administration or in potassium depletion (Georgopoulos, Proudfit, and Page, 1961). However, there is no evidence of potassium depletion in myxoedema (Cohen, 1963). A further possibility is that the changes may be related in some way to the presence of pericardial effusion in hypothyroidism. Kern, Soloff, Snape, and Bello (1949) showed in one patient that the resting changes in the E.C.G. could be immediately partially reversed by the withdrawal of pericardial fluid, and the resting E.C.G. changes can be reproduced by infusion of saline into the pericardial sac of the dog (Hamolsky, Kurland, and Freedberg, 1963). We are unaware of any studies of the exercise E.C.G. in pericardial effusion, and there are obvious difficulties in making such observations. In the present series of patients pre-treatment chest $x$-ray films were available in all except Cases 7,11 , and 13. Two patients showed cardiac enlargement - of moderate degree in Case 3 and of lesser degree in Case 12, in which it was mainly left ventricular. In Case 3 some decrease in the size of the heart was apparent some weeks after the start of treatment. Case 13 had mild hypertension. The part played by pericardial effusion in causing the enlarged heart shadows in these cases is uncertain, since other factors may well have contributed.

In ischaemic heart disease the exercise E.C.G. changes are presumably due to myocardial anoxia. If such anoxia is indeed present in the myxoedematous heart during exercise, a number of mechanisms must be considered: $(a)$ that the anoxia is due to coexistent anaemia ; $(b)$ that obstructive coronary atherosclerosis is more common in myxoedematous patients than in normal persons of the same age group; $(c)$ that coronary blood-flow does not increase normally with exercise in myxoedema ; $(d)$ that in patients with myxoedema more work is necessary to circulate the increased cardiac output on exercise than in normal persons; and (e) that the myocardium does not take up oxygen as readily in myxoedema as normally.

With regard to anaemia, Table I shows that in most of the patients who underwent the exercise test the haemoglobin was greater initially than $11 \mathrm{~g} . / 100 \mathrm{ml}$. In Case 1 (see Fig.), though the haemoglobin was initially low, $8.4 \mathrm{~g} . / 100 \mathrm{ml}$. , and fell to $6.6 \mathrm{~g} . / 100 \mathrm{ml}$. at the time of the post-treatment test, the abnormalities on exercise that were present before treatment had nevertheless disappeared. It does not therefore appear likely that anaemia is a major factor in causing the exercise E.C.G. abnormalities.

There seems to be a widespread belief that myxoedema predisposes to atheroma. If it were true this belief would provide a basis for suggesting that the ischaemic-like changes in the exercise E.C.G. were due to organic occlusion of the coronary arteries. It should at once be pointed out that the reversibility of the exercise E.C.G. changes on treatment is very much against this suggestion. Also there is in fact very little evidence that myxoedema predisposes to the earlier or more severe development of atheroma (Clinical Society of London, 1888 ; Blumgart, Freedberg, and Kurland, 1953 ; Baker and Hamilton, 1957).

With regard to the coronary blood-flow (c) no data are arailable on changes on exercise in myxoedema. There is, however, sc:mewhat better evidence with regard to (d). Graettinger, Muenster, Checchia, Grissom, and Campbell (1958) made detailed haemodynamic studies at rest and on exercise in 12 patients with myxoedema. It may be inferred from their measurements of systemic blood-pressure and cardiac output that the increment of left ventricular work associated with the same amount of exercise is very similar to both normal subjects and myxoedematous patients.

Finally, den Bakker, Sundermeyer, Wendt, Salhaney, Gudbjarnason, and Bing (1962) found that in a resting myxoedematous patient lactate and pyruvate were extracted from coronary-artery blood, but the mvocardium added these substances to the blood when the patient exercised. This suggested that energy was being provided by the glycolysis rather than by oxidative metabolism in exercise. It was shown that in the resting myxoedematous patient some glucose was following metabolic routes other than oxidative, whereas this is not tie case in normal subjects. This fact could be explained either by inadequate blood supply at rest and perhaps on ixercise, or by a failure of the myxoedematous myocardium to take up oxygen even though the supply is adequate. Either explanation would explain the reversible changes in the exercise E.C.G.

From a clinical standpoint it is clear that in myxoedema the exercise E.C.G. cannot be used to gauge whether precipitation of symptoms of ischaemic heart disease is likely during treatment. Virtually all patients in fact show changes in the hypothyroid state which could be interpreted as ischaemic. With regard to this problem the findings of Keating, Parkin, Selby, and Dickinson (1961) are of great interest. Those workers reviewed 1,503 myxoedematous patients from the Mayo Clinic. Of 90 patients who had angina at some stage either before or during therapy 55 had angina before therapy and 35 developed it during therapy. Of the 55 patients with pre-existing angina (mean age 62, range 43-76 years), the angina disappeared on treatment in five and was greatly improved in 16 . In 25 the angina remained unaltered by therapy; it became worse in nine patients. In the group developing angina on treatment the mean age was 71 years. It is therefore difficult to predict the effect of treatment on angina and the liability in the individual case to cardiac ischaemia on treatment. From the point of view of the present study the group in which angina disappeared on treatment is of particular interest; it suggests that ischaemic symptoms before treatment were due to causes other than organic coronary occlusion, and it is noteworthy that the mean age of this group was lower than in the group in which angina was precipitated by treatment. Similar causes may limit the benefit obtained in cases of intractable angina treated by artificial induction of hypothyroidism (Blumgart et al., 1953 ; Strong and Turner, 1962).

\section{Summary}

The effect of exercise on the electrocardiogram has been studied in 13 patients with myxoedema.

In all except one case exercise produced changes which resemble those seen in ischaemic heart disease. These changes on exercise disappeared after treatment.

It is argued that if these changes are in fact indicative of myocardial anoxia in myxoedema, then organic coronaryarterial occlusion is not a major factor in causing the anoxia, at least in the patients studied. It is suggested that in the 
myxoedematous state there may be a metabolic defect resulting in poor tissue-oxygen uptake.

It is unlikely that the exercise E.C.G. can be of help in determining whether a patient is liable to develop symptoms of cardiac ischaemia when treated for myxoedema.

We would like to thank Professor C. Wilson, Dr. W. Brigden, and Professor J. M. Ledingham for helpful discussion. This study formed part of an M.D. thesis (Cambridge) submitted by one of us (R. D. C.).

\section{REFERENCES}

Baker, S. M., and Hamilton, J. D. (1957). Lab. Invest., 6, 218. Blumgart, H. L., Freedberg, A. S., and Kurland, G. S. (1953). Amer. $\mathcal{F}$. Med., 14, 665 .

Clinical Society of London (1888). Trans. clin. Soc. Lond., Suppl. to vol. 21 .
Cohen, R. D. (1963). Clin. Sci., 25, 293.

den Bakker, P. B., Sundermeyer, J. F., Wendt, V. E., Salhaney, M., Gudbiarnason, S, and Bing, R. J. (1962). Amer. F. Med., 32, 822.

Georgopoulos, A. J., Proudfit, W. L., and Page, I. H. (1961). Circulation, 23, 567 .

Graettinger, J. S., Muenster, J. J., Checchia, C. S., Grissom, R. L., and Campbell, J. A. (1958). Ұ. clin. Invest., 37, 502.

Hamolsky, M., Kurland, G. S., and Freedberg, A. S. (1963). In Current Concepts in Hypothyroidism, edited by K. R. Crispell. Pergamon, London.

Keating, F. R., Parkin, T. W., Selby, J. B., and Dickinson, L. S. (1961). Progr. cardiovasc. Dis., 3, 364.

Kern, R. A., Soloff L. A., Snape, W. J., and Bello, C. T. (1949). Amer. f. med. Sci., 217, 609 .

Lloyd-Thomas, H. G. (1961a). Brit. Heart f., 23, 260

Lloyd-Thomas, H. G. $(1961 \mathrm{a})$.

Master, A. M., Field, L. E., and Donoso, E. (1957). N.Y. St. F. Med., 57, 1051.

Robb, G. P., Marks, H. H., and Mattingly, T. W. (1956). Trans. Ass. Life Insur. med. Dir. Amer., 40, 52.

Robertson, J. D., and Reid, D. D. (1952). Lancet, 1, 940.

Strong, J. A., and Turner, R. W. D. (1962). Quart. F. Med., 55, 22.
Ataxia-telangiectasis is an autosomal recessive disorder characterized by gradually progressive cerebellar ataxia in childhood (Wells and Shy, 1957; Boder and Sedgwick, 1958) and telangiectasis secondary to venule dilatation (Louis-Bar, 1941 ; Williams et al., 1960). These children often manifest impaired immune competence. They have an increased incidence of sinopulmonary infections (Gutmann and Lemli, 1963), undetectable or abnormal serum IgA $(\beta-2 A)$ immunoglobulin levels (St. Thieffry et al., 1961), diminished delayed hypersensitivity reactions, delayed and prolonged skin-homograft rejection, and occasionally peripheral lymphopenia (Fireman et al., 1964 ; Young et al., 1964 ; Eisen et al., 1965). Absence or hypoplasia of thymic and lymphoid tissues, and an increased incidence of malignant lymphoma among these patients, have also been described (Peterson et al., 1964).

The lymphocyte plays an important part in immune reactions (Gowans et al., 1962). Small lymphocytes can be stimulated to transform in vitro to large blast cells, which may undergo mitoses. This response can be elicited both by non-specific stimulants such as phytohaemagglutinin (Nowell, 1960 ; Ling and Husband, 1964) and by specific antigens to which the cell donor has been previously exposed (Pearmain et al., 1963 ; Elves et al., 1963). Impaired lymphocyte transformation has been reported in patients with various immunological and lympho-proliferative disorders such as primary hypogammaglobulinaemia (Fudenberg and Hirschhorn, 1964 ; Ling and Soothill, 1964), Boeck's sarcoid and lymphomas (Hirschhorn et al., 1964), and chronic lymphocytic leukaemia (Oppenheim et al., 1965a, 1965b). We have tested the response to phytohaemagglutinin and various antigens of lymphocytes cultured from the peripheral blood of patients with ataxia-telangiectasis to characterize further their immunological deficiency.

\section{Patients Studied}

The peripheral leucocytes of five untreated patients with characteristic ataxia-telangiectasis were repeatedly tested and compared with those obtained from 18 normal young adults. The patients ranged in age from 10 to 19 . Two of them were sisters, and the others were unrelated. All had received childhood immunizations with diphtheria, pertussis, and tetanus and vaccinia vaccine without sequelae, and had had the common childhood viral infections without complications. Two of the patients had histories of frequent pulmonary and middle-ear infections. These had not recurred for three years prior to this study. One of the patients had a questionable allergic history of "rose fever" in the spring, and skin eruptions after ingesting chocolate.

Mediastinal tomography failed to reveal any thymic enlargement. The pharyngeal tonsillar tissue was decreased in all patients. None had peripheral lymphadenopathy. One of the patients was lymphopenic, with a mean of 810 peripheral lymphocytes per c.mm. Bone-marrow aspirations in the four patients examined were normal and contained plasma cells. All patients lacked detectable serum IgA immunoglobulin by immunoelectrophoretic and immunodiffusion techniques. The lymphopenic patient had hypogammaglobulinaemia by serumprotein electrophoresis. All patients had low normal isoagglutinin and febrile agglutinin titres. They were all anergic to intradermal tests with blastomycin, histoplasmin, coccidioidin, mumps antigen, trichophyton, second-strength purified protein derivative, and trichinella extract. In the three subjects tested 2,4-dinitrochlorobenzene skin-sensitization elicited a normal reaction. They also rejected first-set, split-thickness, 8-mm. punch-biopsy skin homografts in normal fashion within 21 days. There was no evidence of malignant lymphomatous disease in any of the patients.

\section{Methods of Culturing Leucocytes}

From each of the five patients $30-50 \mathrm{ml}$. of venous blood was obtained on three to six different occasions over a nine-

\footnotetext{
* Medicine Branch, National Cancer Institute, National Institutes of

Health, Bethesda, Maryland. Institutes of Health Bethesda, Maryland.

Institutes of Health, Bethesda, Maryland.
$\ddagger$ Metabolism Service, National Cancer Institute, National Institutes of Health, Bethesda, Maryland.
} 